1 Ideas Alliance

2 Bromley

Cite this as: BMJ 2021;375:n2954 http://dx.doi.org/10.1136/bmj.n2954 Published: 30 November 2021

PARTNERSHIP IN PRACTICE

\title{
Improving support for children with autism and their families using a 100 day challenge framework
}

\begin{abstract}
Community-based support for autistic children and their families can prevent individuals from reaching crisis point and reduce inpatient admissions. ${ }^{1}$ Lauren Wallace-Thompson and Jason Rose describe how they set up a joint initiative with Bromley Council and the parents and carers of children and young people with autism, and what changes this has introduced.
\end{abstract}

Lauren Wallace-Thompson, ${ }^{1}$ Jason Rose $^{2}$

\section{Lauren Wallace-Thompson, communications and content manager, Ideas Alliance:}

Autism spectrum disorders (ASD) affect approximately 1 in 160 children and it is estimated that there are around 700 ooo autistic adults and children in the UK. ${ }^{23}$ Autism is a life-long condition and its severity varies. Support services, including short breaks services to give carers respite, mental health support, speech and language therapy, educational psychology, and needs assessment of families all help, but are often difficult to access. Waiting lists are long and services often poorly coordinated. ${ }^{45}$ The average delay between a parent approaching a health professional with concerns, to confirmation of an ASD diagnosis is 3.5 years, and one study found that $35 \%$ of families were offered no support post-diagnosis. ${ }^{6}$

Evidence shows that parents of children with autism are at appreciable risk of poor mental health, and unsatisfactory service interactions exacerbate their problems. ${ }^{7}$ Mothers of children with autism report lower levels of satisfaction with service interactions than those of children with other disabilities, and parents are more likely to be hospitalised for mental disorders than those of neurotypical children. ${ }^{7}$ Bromley is a borough in the South East of England with over 330 ooo residents, and the experience for families here has been similar to that of thousands of families across the UK: long waiting times for diagnosis and specialist services, parents battling over scarce resources and support, and stretched budgets. In 2019, leaders of One Bromley, a partnership of health and social care services and the voluntary sector who coordinate the support for these families, felt that they had become frozen into endlessly discussing problems with no action or solutions. To help, they reached out to Ideas Alliance, a social enterprise that partners with councils, service providers, and other organisations to promote and instigate collaborative and community-based methods of working.

As facilitators, Ideas Alliance recognised that the work needed to be action-based straight away. In the latter half of 2019, we ran a 100 day challenge with parents, professionals, and local authority leaders focusing on support for families of children with autism in Bromley. In this model, services and stakeholders work together to rapid test improvements and changes over a 100 day period. The model was pioneered by the Rapid Results Institute and Nesta (an organisation that supports innovation for social good) and is based on the principle that "frontline practitioners and people who use public services have unrivalled expertise in how the system operates, but often have little influence or ownership over change." ${ }^{8}$ During the 100 days, those closest to delivery are empowered and connected to drive change.

Nesta have been using and testing this approach since 2015. The 100 day challenge has a defined framework and is conceived of as a "sprint": the idea is to spend far more time doing than talking. This is important both for achieving results (and change) quickly, but also because the act of doing in itself spurs further action. Going in, neither the facilitators nor the council know what will happen-that is down to the group.

\section{Implementing the 100 day challenge}

We started by setting up a discovery workshop open to anyone working with or looking after children and young people with autism, and this was advertised by the council through their networks. More than 50 people attended, including parents, carers, and staff from the voluntary sector, council, and local clinical commissioning group (CCG) staff and schools. The aim of the workshop was to bring people together and understand what wasn't working, why, and explore the potential to co-design solutions to the problems identified. The group selected the issue of autism-awareness-tying into education and training-as their primary focus for the challenge. We used techniques like power-levelling exercises and storytelling to redistribute the authority within the room and create a space for collaboration as equals.

A regular group was then established to work on potential solutions using a rapid-testing process. The group, which had 10-12 core members, met every two weeks. A lot of the facilitation in the challenge was about building relationships and every session started with activities to cement relationships. Over time, our facilitation decreased to encourage the group to own its own processes and actions. 
All participants were invited to join 50 and 100 day milestone celebrations to share learning with sponsors and wider stakeholders. At these informal meetings one team made a video to show and another shared personal experiences and stories.

\section{Changes catalysed by the challenge}

- Bromley Council transformed ownership of its autism governance and strategy from separate, professional-driven boards for adults and children, into a new autism partnership board that covers all ages, has people with autism on the board, and is chaired by a parent.

- A co-designed training and development programme about autism using immersive theatre and designed to be accessible to a wide audience. implementation was disrupted by covid.

- An ongoing partnership with the local shopping centre, including the introduction of sunflower lanyards to raise awareness of hidden disabilities, and permission to use a vacant space at the centre once a year to hold a learning week, during which information resources about autism are made available and visitors have the opportunity to speak with SEND (Special Educational Needs and Disability) staff from across the borough to get a better understanding of the condition. In 2020, the learning space had over 300 visitors.

- A parents' written guide to coping outside the home, links to useful local services (and delineation of rights to access them).

- A film, documenting the 100 day challenge and showing what was and what wasn't working for families in the Borough, illustrated by personal stories

- Establishment of a parent peer support group. Immediate post-diagnosis peer groups and schools peer groups were also set up.

- One headteacher of a local school has arranged for their next conference to be about autism.

\section{Jason Rose, parent participant:}

I am a parent of two boys with autism and I have long struggled to get the care and support the family needs. At every stage it felt like obstacles were being put in the way and that the focus of the local authority was saving money, not supporting my children. I had to go to Tribunal to secure the right provision in my younger son's Education and Health Care Plan (EHCP); and that was after having successfully challenged the content of the speech and language, occupational therapy, and educational psychologist's professional reports, as not being compliant with the statutory guidance set out in the SEND Code of Practice.

Being part of the Bromley 100 day challenge team helped me realise that the professionals who run services were passionate about delivering good outcomes, but were prevented from doing so by lack of funds, bureaucracy, and lack of understanding of what was needed. I met some highly motivated, knowledgeable people who also wanted to fix things. There were also other parents who'd had different experiences and it was a good opportunity to learn from them, and share information with them.

One parent recalled that, at the meeting where they were given their child's diagnosis, they were provided with a photocopied sheet which covered how many marriages fail when parents care for an autistic child, but gave no practical advice. A working group, led by parents, started to collate the information they wish they had been given. This led to the production of a booklet provided to the parents of every child diagnosed in the borough. It provides details of support organisations and useful services e.g. special quiet shoe fittings for autistic children.

The largest shopping centre in the borough adopted the sunflower lanyard scheme following training delivered by some of the project team. Bromley Council are now planning to roll out an accreditation scheme for retailers and service providers.

None of the above would have happened as quickly, if at all, without the pressure to deliver in 100 days. It is worth noting that the project team was not given any funding-we had to come up with ideas that were no/very low cost. There were times when I doubted that the project would deliver anything meaningful: the number of people actively engaged dropped as the project went on and there were a few blind alleys.

Since the end of the project I have gone on to chair the Bromley All-Age Autism Partnership Board, a multi-faceted group of professionals, parent/carers, and people with autism. This is the first such board in the borough to be chaired solely by a stakeholder rather than a professional or council member.

\section{Learning points and future directions}

The rapid nature and action-based approach of the 100 day challenge resulted in innovative changes to improve understanding and support for and families of children with autism and enabled those who live with autism to play an active part in shaping support and community-based services.

External facilitators can help catalyse change within an organisation with a history of difficult relationships, and navigate challenges like tight budgets and patterns of inaction.

Bromley are just about to launch their second 100 day challenge, around supporting people with autism into employment.

\section{Key messages:}

A 100 day challenge is a quick, action-driven process involving mixed teams of different stakeholders working on an issue that is important to them to create change.

In Bromley, the 10o day challenge produced several specific outputs that have the potential to improve the lives of families of children with autism.

The most important change has been in the relationships that have been built, resulting in the creation of an all-ages autism partnership board chaired by a parent.

Competing interests: none declared

Provenance and peer review: Commissioned, not peer reviewed

This article is part of the partnership in practice series.

Long Term Plan NHS. 2019 'Learning disability and autism'

https://www.longtermplan.nhs.uk/online-version/chapter-3-further-progress-on-care-quality-and outcomes/a-strong-start-in-life-for-children-and-young-people/learning-disability-and-autism/

2 WHO. 'Autism Spectrum Disorders' https://www.who.int/news-room/fact-sheets/detail/autismspectrum-disorders

3 Local Government Association. 'National strategy for autistic children, young people, and adults: 2021 - 2026' https://www.local.gov.uk/our-support/sector-support-offer/care-and-health-improvement/autistic-and-learning-disabilities/autistic/strategy

4 Guidance NICE. Autism spectrum disorder in under 19s: support and management Recommendations https://www.nice.org.uk/guidance/cg170/chapter/Recommendations

Suffolk County Council apologises for special needs failings' BBC News https://www.bbc.co.uk/news/uk-england-suffolk-58622684

6 Crane L, Chester JW, Goddard L, Henry LA, Hill E. Experiences of autism diagnosis: A survey of over 1000 parents in the United Kingdom. Autism 2016;20:153-62. doi: 10.1177/1362361315573636. pmid: 25810370 
7 McKenzie R, Dallos R, Stedmon J, etal. SAFE, a new therapeutic intervention for families of children with autism: a randomised controlled feasibility trial. BMJ Open 2020;10:e038411.

doi: 10.1136/bmjopen-2020-038411. pmid: 33384385

8 NESTA. 'People Powered Results: The 100 Day Challenge': https://www.nesta.org.uk/feature/innovation-methods/people-powered-results/ 